\title{
A model for teaching medical ethics
}

\author{
R B Welbourn Emeritus Professor of Surgical Endocrinology, Royal Postgraduate Medical School
}

\section{Author's abstract}

The approach to teaching employed in the Dictionary of Medical Ethics (1) provides a model which might be adopted in other media. Most of the 150 authors were medical, but many represented other disciplines, and they wrote for similar professionals and for the general public. Medical ethics is derived from medical science and practice, moral philosophy, sociology, theology, the law and other disciplines, all of which make essential, distinctive and complementary contributions to knowledge and to teaching. Medical practitioners must play the primary role, because they are responsible for clinical ethical decisions, but they need the co-operation and guidance of others. All who are concerned should work towards the development of a general moral consensus among the profession and public, which keeps abreast of scientific and technical advances and to which all are committed.

My main experience in teaching ethics is as one of the editors of the Dictionary of Medical Ethics (1). About 150 people contributed and I learned far more from them and from my fellow editors than I taught. We had three main principles in planning the work.

1) We were writing primarily for the medical profession where study and education must start, but we were writing also for medical students and for members and students of the paramedical disciplines. We also had many other people in mind: ministers of religion, lawyers, medical administrators, members of Parliament, journalists, and the general public who come to us as patients.

2) By the term 'medical ethics', we understand the moral obligations which govern the practice of medicine. We all share these in common, and our fellow doctors and society as a whole expect us to honour them. In the past people generally assumed that professional ethics was a natural inbred part of every doctor's equipment and that, in what they understood as the Hippocratic tradition, we cared for our patients above all else and knew what this involved. There were of course exceptions, for instance in the way we failed to care

\section{Key words}

Medical ethics; medical education. adequately for people dying in general hospitals, and $\widehat{\bar{\Im}}$ there were abuses. But medicine was much simpler $\vec{\square}$ then, and, in general, I think that this view contained an element of truth. In so far as medical ethics was iु taught, it was often identified with medical etiquette, with law and, for some groups, with religious instruction. It is, of course, related to all these but, as editors of the Dictionary, we were very conscious of the fact that, in recent years, medical and scientific $\frac{\rho}{\rho}$ progress had been so great and so rapid that practices $\vec{\varphi}$ undreamt of when we were young were now in common use and had brought with them new moral dilemmas which no one, including the doctors, the lawyers and the theologians, had had time to define, let alone resolve. This process seemed certain to continue, the general public was concerned about it, and we felt that it was time to take stock. In fact, it was our $\stackrel{D}{\circ}$ publisher, Mr John Todd, a thoughtful layman, who $\overrightarrow{\bar{O}}$ conceived the idea of the Dictionary, and we readily agreed to co-operate.

3) Medical ethics is derived from several disciplines, each with its own origins, objectives, traditions and methods of work. All of them are essential and none is $\mathbb{\Phi}$ adequate alone. The first is medicine itself, which we all understand. It provides knowledge of the scientific aspects of the problems with which we deal; and we clinicians, together with our paramedical colleagues,

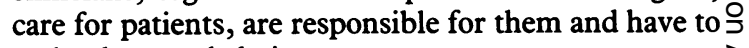
make the moral choices.

The second discipline is ethics, or moral philosophy, which is concerned with the formal study of morality, ${ }_{0}$ the nature of ethical arguments and the analysis of $N$ universal principles and concepts. Doctors know little about this, but it is vital for two reasons: (i) It seeks to $\mathrm{W}$ put into perspective the particular beliefs, attitudes? and codes or rules of different societies, groups ande individuals; (ii) It provides a background of principles against which particular issues may be seen and ${ }^{+}$ individual moral choices made. It helps us to see in $\frac{0}{0}$ immediate problems the moral dilemmas of all time.

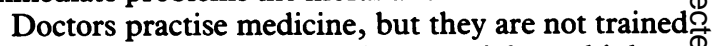
in moral philosophy, and we have no right to think, as $\overparen{\mathbb{}}$ some do, that problems which have puzzled great thinkers through the ages can be solved by so-calledo common sense or by the voice of conscience. If theyO could, there would not be so many different solutions 
to the same problems. Conversely, philosophers are not trained in medicine, and they are not competent to decide medical ethical issues on their own. In the United States the emphasis is usually reversed and philosophers play the leading role in the study of medical ethics or, as they call it, bioethics.

Other important disciplines, which have much to contribute, are theology and social science. The other major one is the law, which reflects the views of society about the rights and wrongs of many aspects of medical practice. If defines what is allowed or not allowed by the State, and protects both patients and doctors. Law and morality are not the same thing. For instance, therapeutic abortion is not right or wrong because the law says so, and issues like consent have both legal and ethical aspects, which are not the same. In North America the law influences the practice of medicine in general much more than it does here, both by legislation and by litigation. I feel that this tends to undermine confidence between patients and doctors, to restrict professional freedom unduly and, on the whole, to do more harm than good. A better alternative, from which patients and doctors will benefit, is for us to promote the study and growth of medical ethics so that a general moral consensus develops among the profession and the public, which keeps abreast of scientific and technical advances.

The general public, of course, have an essential contribution to make and, as we said in the Dictionary, 'the health of the people is the concern of the people'. We must always attend to what our patients and the public have to say, and Parliament, which makes the laws, represents the people politically.

Our approach, then, in planning the Dictionary was multidisciplinary. Of the three editors, two of us were university clinical professors, Professor Duncan and myself, and one was a moral and social theologian, Professor Dunstan. Nearly three quarters of the contributors were medical practitioners and scientists who wrote about their own subjects. We started with two introductory articles, one on medical science and one on medical ethics, to set the scene. Then we took the topics alphabetically. Often the medicals opened up the discussions and set out what they saw as the ethical dilemmas. The other contributors were philosophers, lawyers, theologians of different faiths, sociologists and many others, and we called on them, as appropriate, to analyse the issues in the light of their own disciplines. Let us take as an example the first entry, 'Abortion'. Dame Josephine Barnes started with an article written from the point of view of a practising obstetrician. Then Professor Dunstan followed with a shorter one, from his professional standpoint, as a moral and social theologian, on General Ethical Considerations. Both gave several other references for further reading. In the course of these articles there are cross-references to others in the Dictionary - on the papal encyclical Humanae Vitae, Amniocentesis, Down's syndrome, Child
Chromosomal disorders, Congenital malformations, Contraception, Research on the fetus, Genetic disorders, Infanticide, Sterilisation and the Rights of the unborn child. These were written by a journalist, a physiologist, two geneticists, two paediatricians, an oncologist, a family planning physician, two gynaecologists, a philosopher and a lawyer.

I feel that this approach embodies the essential elements involved in teaching medical ethics, and provides a model for doing it in one medium - the Dictionary - which may be adapted for others. However, I want to make four more points.

a) In medical education in general, we have always encouraged sound clinical judgement, based on knowledge of medical science and on experience of clinical practice. Similarly today, we should also encourage sound ethical judgement, based on knowledge of the nature of ethical analysis and argument in general, on the study of particular moral issues in medical practice, and, most importantly, on first-hand experience of the problems of individual patients. One person's clinical judgement, however sound, often differs from that of another. Similarly ethical judgements may also vary, but we should aim to educate doctors in such a way that they develop rational and analytical skills which enable them to engage in informed and sensitive ethical discussions among themselves, with members of other professions, with people in general and with their patients. This does not mean that they will necessarily reach 'right' decisions, because often there is no single right one; but it does mean that they should know how to analyse the issues involved so that they understand thoroughly the alternatives from which they have to choose.

b) Teachers must be drawn from all the relevant disciplines, and they must be interested people who have made a special study of medical ethics. At present there are not enough qualified teachers to meet adequately even the modest recommendations of the General Medical Council about teaching ethics. The main burden of teaching must lie on the doctors, who look after patients and who take the decisions. But they need help from moral philosophers, lawyers, theologians, social scientists and others. As in all adult education, where there are different, often contradictory, and sometimes prejudiced views, it is important to bring people together for public discussion and debate, about particular issues and individual cases. I consider it less than ideal that people who do not look after patients, and who do not themselves have to take moral decisions about them, should have the major responsibility for teaching medical ethics. In Eire, for instance, where ethical teaching is taken seriously, I understand that most of it is done by priests. It is right and proper for a Church or any other religious body to instruct its members in its doctrine and moral code, but there is much more to medical ethics than this. Then, in North America, the teachers are mainly so-called 'ethicists', whose knowledge is largely theoretical. Recently I spoke to 
one who took a course in 'dying, death and grief'. Since I myself teach only subjects which I practise, I asked him if he had a pastoral role in the hospital. 'Oh no', he said, 'that's the chaplain's job'.

c) The subject matter of medical ethics is vast and there are over two hundred entries in the Dictionary, from 'Abortion', to 'World Medical Association', and including 'General Medical Council' and 'Teaching medical ethics'. I want to pick out one topic, which has to do with most of the others. This is the collection of codes of conduct to which we all subscribe, at least in theory: the Hippocratic Oath, the Nuremburg Code, the declarations of the World Medical Association, and so on. These are excellent summaries of our primary aims and they need to be studied in detail, but they fail to provide answers to the really difficult moral problems in medicine, because they use, but do not define, terms like 'life', 'respect', 'health', 'suffering', 'rights', 'duties' and 'the laws of humanity' (2). These are all basic concepts which require careful philosophical analysis, and the teaching of ethics should help doctors to understand them, not just to give them lip service because they sound worthy.

d) Learning, like teaching, medical ethics should be multidisciplinary. We have much in common with nurses, clergy, lawyers, medical administrators and other people, which they and we need to learn. For instance, would not legislators and administrators, like us, benefit from learning the ethical principles involved in the allocation of resources and in keeping medical records confidential? I have taken part in ethical discussions with lawyers, clergy, nurses and the general public, at local and international meetings, which included all these groups, and I think that most of us have learned much from each other.

In conclusion, medicine is - or should be - a learned and a caring profession. Medical ethics and its teaching are not simply hobbies for the few, but vital to the practice of good medicine by us all. Medical ethics is a discipline, based on clinical practice and drawing on moral philosophy, theology, law, sociology and other branches of learning. It is everyone's concern and must develop and keep pace with advances in medical science and practice.

\section{References}

(1) Duncan A S, Dunstan G R, Welbourn R B. Dictionary of Medical Ethics. Revised and enlarged ed. London: Darton Longman and Todd, 1981; paperback edition, Darton Longman and Todd, 1983. The American edition, hardback, New York: Crossroad, 1981 is the same as the English edition apart from an extra foreword.

(2) Campbell A V. Moral dilemmas in medicine. 2nd ed. Edinburgh, London, New York: Churchill Livingstone, 1975. 